\title{
Position and Speed Control of Infusion Pump Actuator for Biomedical Applications
}

\author{
Mahmut ÜN, Çağlar Çiftçioğlu
}

\begin{abstract}
Main focus of this paper is control of infusion pump actuator (IPA) for biomedical applications. Control of IPA done using position regulator and control which combine position and speed regulator is proposed. The main guideline is to decrease power losses, heating and current consumption in the system. One of the important areas within the field of variable speed motor drives are the operational boundaries of system. Presently, the operational boundaries of variable speed motor drives are set based on the operational boundaries of single speed motors, i.e. by limiting current and power to rated values. This results in under-utilization of the system, and places the motor at risk of excessive power losses. In this paper, the first part represents general concept of infusion pump actuators and mathematical modeling of the system, then the control of position and speed of infusion pump actuator (IPA) by using fractional order PID controller is presented. The second part shows simulations of our own design of control speed and position by fractional order PID controller using SIMULINK and MATLAB software. Finally fractional order PID regulator results are compared with classical PID regulator results
\end{abstract}

Index Terms - DC motor, infusion pump actuator (IPA), PID controller, FOPID controller, position control, speed control, combine position and speed regulator, simulations

\section{INTRODUCTION}

In reference to the literature $([1,2]$ and many others not cited here), for the better part of $20^{\text {th }}$ century most motion control systems were designed to operate at a fixed speed. Many existing systems still operate based on a speed determined by the frequency of the power grid. However, the most efficient operating speed for many applications, such as fans, blowers and centrifugal pumps, is different from that enforced by the grid frequency. Also, many high performance applications, such as robots, machine tools and the hybrid vehicle, require variable speed operation to begin with. As a result, a major transition from single speed systems to variable speed systems is in progress.

The transition from single speed drives to variable speed drives has been in effect since the 1970s when movements towards conservation of energy and protection of the environment were initiated. About seventy percent of all electrical energy is converted into mechanical energy by motors in the industrialized world. This may be the most important factor behind today's high demand for more efficient motion control systems. A large body of research is available on variable speed drives due to the significant industrial and commercial interest in such systems.

Mahmut ÜN, İstanbul Yeni Yüzyıl University, Faculty of Engineering and Architecture, Topkap1 / Istanbul 34010, Turkey

Çağlar Çiftçioğlu, İstanbul Gelişim University, Health Occupation High-School, Avc1lar / Istanbul 34310, Turkey
However, some areas of importance merit further investigation. One such area is the operational boundary of motor drives. The operational boundaries of variable speed motor drives are being incorrectly set based on the operational boundaries of single speed motor drives, i.e. by limiting current and power to rated values. The operational boundary of any motor drive must be set based on the maximum possible power loss vs. speed profile for the given motor. Also, all control strategies for a machine must be analyzed and compared based on such an operational boundary [3].

The mechatronic systems represent one of the most challenging control applications due to their interdisciplinary nature $[4,5,6]$. Numerous control algorithms have been proposed to deal with nonlinear Dynamics of the mechatronic systems. For linear mechatronic systems, the proportional-integral-derivative (PID) controller is often used owing to its simple structure and robustness [7]. Another approach in dealing with mechatronic systems challenges is the fractional-order (FO) control strategies. One of the most common applications in all mechatronic domains is the control of DC motors. The control of DC motors has been the interest of many researchers, due to the wide variety of applications that require the use of different types of DC motors $[8,9,10]$. The controllers designed for these DC motors range from simple traditional PIDs to advanced control algorithms, among which fractional order control has been gaining more and more popularity $[11,12,13]$.

Fractional calculus has been used relatively recently in modeling and control applications [14, 15]. The attractiveness of the fractional order PID controllers resides in their potential to increase the closed loop performance and robustness of the closed loop system, due to the extra tuning parameters available, as compared to the conventional controller. With fractional order controllers, the order of differentiation and integration may be used as supplementary tuning parameters and thus more specifications can be fulfilled at the same time, including the robustness to plant uncertainties, such as gain and time constant changes $[16,17$, 18]. In general, frequency domain tuning of the fractional order controllers is preferred using optimization routines to yield the final solutions. The performance criteria are frequently specified in terms of gain crossover frequency, phase crossover frequency, phase margin, gain margin, robustness to open loop gain variations $[19,20]$.

However, some areas of importance merit further investigation. One such area is the operational boundary of motor drives. The operational boundaries of variable speed motor drives are being incorrectly set based on the operational boundaries of single speed motor drives, i.e. by 
limiting current and power to rated values. The operational boundary of any motor drive must be set based on the maximum possible power loss vs. speed profile for the given motor. Another area is the regulator design for the speed and position. Also combine speed and position regulator design is to impose some additional control on the same system. Recently researches for speed and position regulators are focused on fractional order PID and classical PID regulators $[21,22]$. Therefore combine speed and position control of IPA is design and tested by using fractional order PID as well as classical PID

The paper is structured as follows: Section II introduces general concept and IPA mathematical model, section III presents the tuning methods for the fractional order PID controller, with the position control for a DC motor. Section IV presents MATLAB design of combine speed and position regulators with fractional order PID and classical PID. Section V presents SIMULINK and MATLAB simulations, while the last section includes the final conclusions.

\section{GENERAL CONCEPT AND MATHEMATICAL MODEL OF IPA}

Linear actuator is a device that applies force in a linear manner, as opposed to rotationally like an electric motor. Electro-mechanical actuators are similar to mechanical actuators except that the control knob or handle is replaced with an electric motor. Rotary motion of the motor is converted to linear displacement of the actuator.

\section{A. Mathematical Model and Control of Infision Pump System}

a) DC Motor Speed and Position Control

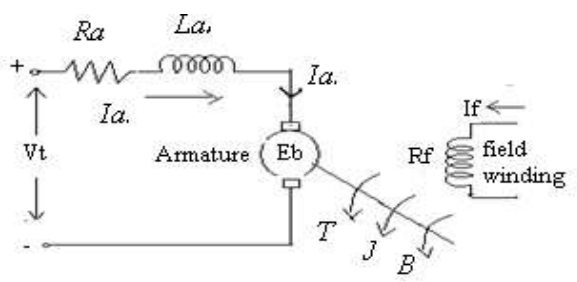

Fig 1. DC motor model.

A general model of a DC motor is shown in Figure1. Applied voltage $\mathrm{V}_{\mathrm{a}}$, which is the manipulated variable, For the position conrol $\Theta(t)$, which is the control variable. For the speed control, the controlled variable is the angular velocity $\mathrm{w}(\mathrm{t})$ and the load transfer function has the form in (1):

$$
\mathrm{G}(\mathrm{s})=\frac{\mathrm{W}(\mathrm{s})}{\mathrm{Va}(\mathrm{s})}=\frac{\mathrm{Km}}{(\mathrm{L} a \mathrm{~s}+\mathrm{Ra})(\mathrm{J} \mathrm{s}+\mathrm{b})+\mathrm{KbKm}}
$$

However, for many dc motors the time constant of the armature $\tau_{\mathrm{a}}=\mathrm{L}_{\mathrm{a}} / \mathrm{R}_{\mathrm{a}}$ is negligible and therefore the model can be simplified to :

$$
G(s)=\frac{K d e}{\pi g+1}
$$

Where $\tau=J R_{\mathrm{a}} /\left(\mathrm{R}_{\mathrm{a}} \mathrm{b}+\mathrm{K}_{\mathrm{b}} \mathrm{K}_{\mathrm{m}}\right)$ and $\mathrm{K}_{\mathrm{dc}}=\mathrm{K}_{\mathrm{m}} /\left(\mathrm{R}_{\mathrm{a}} \mathrm{b}+\mathrm{K}_{\mathrm{b}} \mathrm{K}_{\mathrm{m}}\right)$

The transfer function from position $\Theta(t)$ as output (controlled variable) to armature voltage $\mathrm{V}_{\mathrm{a}}$ as input (manipulated variable) will be :

$$
G(s)=\frac{\theta(s)}{V a(s)}=\frac{K d c}{s(\tau s+1)}
$$

Injection $\mathrm{mg}$ is calculated based on $10 \mathrm{cc}$ injector. The dose formula for the infusion pump mechanism shown in Figure 2 is given by (4).

$$
\operatorname{Dose}(\mathrm{mg})=(\theta / 2 \pi) \mathrm{a} \cdot \pi r_{\theta n}^{2} d_{\text {ila }}
$$

Where, the angular position of the $\theta$ (rad) shows the screw density, the screw pitch a $(\mathrm{mm})$, the injector radius $\mathrm{r}_{\mathrm{en}}(\mathrm{mm})$ and the drug concentration $\mathrm{d}\left(\mathrm{mg} / \mathrm{mm}^{3}\right)$.

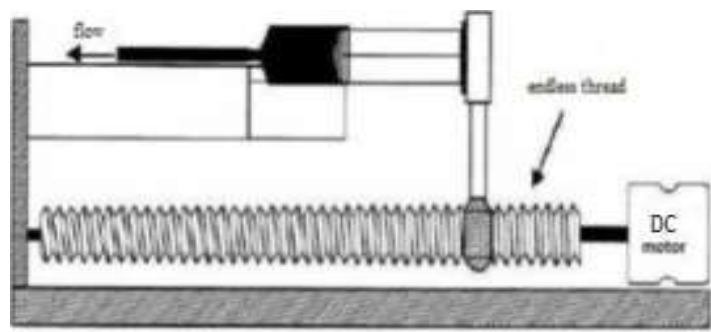

Fig 2. Syringe infusion mechanism [8].

In this study, a syringe mechanism was used to serve as the fluid reservoir and to create the necessary pressure for infusion. It uses an endless worm thread to position the plunger, managing in this way the liquid movement. This process is controlled by a dc motor where the rotation of the motor is transmitted to the endless thread (Figure 1. ). Normally, a spring is used to push the plunger with a constant force, necessary for a stable infusion pressure. This type of infusion generates a continuous high precision flow (with an error below $2 \%$ ).

\section{FRACTIONAL ORDER PID CONTROLLER DESIGN}

The fractional order $\mathrm{PI}^{\lambda} \mathrm{D}^{\mu}$ controller $[15,16]$ was proposed as a generalization of the PID controller [2] with integrator of real order $\lambda$ and differentiator of real order $\mu$. The transfer function of such a type controller in the Laplace domain takes the form

$$
\mathrm{G}_{\mathrm{c}}(\mathrm{s})=\mathrm{K}_{\mathrm{p}}+\mathrm{K}_{\mathrm{i}} \mathrm{s}^{-\lambda}+\mathrm{K}_{\mathrm{d}} \mathrm{s}^{\mathrm{p}}
$$

Here $\mathrm{k}_{\mathrm{p}}, \mathrm{k}_{\mathrm{i}}, \mathrm{k}_{\mathrm{d}}$ denote the proportional, integral and differential gains of the controller respectively. $k_{p}, k_{i}$ and $k_{d}$ parameters usually take non-negative values. Taking $\lambda=1$ and $\mu=1$ we obtain a classical PID controller. If $k_{d}=0$ or $k_{i}=$ 0 we obtain $\mathrm{PI}^{\lambda}$ controller or $\mathrm{PD}^{\mu}$ controller, respectively. All these types of controllers are particular cases of the $\mathrm{PI}^{\lambda} \mathrm{D}^{\mu}$ controller. In this paper we use the both $\mathrm{PD}^{\mu}$ and $\mathrm{PI}^{\lambda}$ controllers, whose transfer function have the form, respectively

$$
G_{c}(s)=k_{p}+k_{d} s^{p} \quad, \quad G_{c}(s)=k_{p}+k_{i} s^{-1}
$$

The block diagram of the considered feedback control system is shown in Figure 3, where $G_{p}(s)$ has form (1) and $\mathrm{G}_{\mathrm{c}}(s)$ has form (5). 


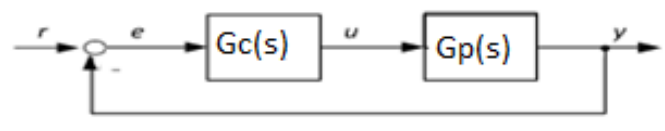

Fig. 3. Feedback control system structure

\section{A. FOPID Controller Design in Frequency Domain}

In the frequency domain design method for fractional areas, the controllers first start with the linear model of the system. The transfer function of the $\mathrm{G}_{\mathrm{p}}(\mathrm{s})$ and $\mathrm{G}_{\mathrm{c}}(\mathrm{s})$ controllers supports the properties of the following equations.

a) An imposed phase margine of the open loop system

$$
\arctan \left(G_{c}(j \omega) G_{p}(j \omega)\right)=-\pi+p m
$$

b) An imposed gain crossover frequency of the open loop system

$$
\left|\mathrm{G}_{\mathrm{c}}(\mathrm{j} \omega) \mathrm{G}_{\mathrm{p}}(\mathrm{j} \omega)\right|=0 \mathrm{~dB}
$$

c) A condition for robustness to gain variation

$$
\frac{\mathrm{d}}{\mathrm{d} \omega} \arctan \left(\mathrm{G}_{\mathrm{c}}(\mathrm{j} \omega) \mathrm{G}_{\mathrm{p}}(\mathrm{j} \omega)\right)=0
$$

d) An imposed remove high frequency noise

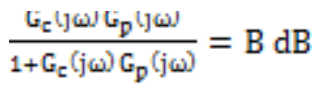

e) An imposed remove the output distortion

$$
\frac{1}{1+G_{c}(j \omega) G_{p}(j \omega)}=A d B
$$

Controller saturation determines the physical systems of the agents. For the motor-generator system, the control operation is limited to $10 \mathrm{~V}$. All equations should be used from the equation (7) to the equation (10) to design features such as phase margin, frequency shift gain, amplitude of sensitivity function (A) and size of complementary sensitivity function (B) for efficient desired design features of the FOPID controller

\section{B. Parametric Synthesis of FOPID Controller}

The asymptotic stability is the basic requirement of a closed-loop system. Gain and phase margins are measures of relative stability for a feedback system, therefore the synthesis of control systems is very often based on them. In typical control systems the phase margin is from $30^{\circ}$ to $60^{\circ}$ whereas the gain margin is from $5 \mathrm{~dB}$ to $10 \mathrm{~dB}$.

In this paper we tuning the controller for the specified phase margin, because a phase margin is closely related to a transient response, i.e. overshoot. For this purpose we use the phase margin tester $\exp (-j \phi)$, where $\phi$ is a phase margin. This tester does not exist in the real control system, it is only used for the controller tuning.

Taking into account the phase margin tester $\exp (-j \phi)$ in the main path of control, plant (1)and controller (3) we obtain the characteristic polynomial of the closed-loop system

$$
w(s)=e^{-j \phi} K\left(k_{p}+k_{d} s^{\mu}\right)+s(s \tau+1) .
$$

Using the classical $D$-partition method the stability region in the parameter plane $\left(k_{d}, k_{p}\right)$ may be determined and the parameters can be specified. The stability boundaries are curves on which each point corresponds to polynomial (4) having zeros on the imaginary axis. It may be the real zero boundary or the complex zero boundary. It is easy to see that polynomial (4) has zero $s=0$ if $k_{p}=0$ (the real zero boundary). The complex zero boundary corresponds t8o the pure imaginary zeros of (12). We obtain this boundary by solving the equation

$$
w(j \omega)=e^{-j \phi} K\left(k_{p}+k_{d}(j \omega)^{\mu}\right)+j \omega(j \omega \tau+1)=0,
$$

which we get by substituting $s=j \omega$ in polynomial (12) and equating to 0 . The complex Equation (13) can be rewritten as a set of real equations in the form

$$
\operatorname{Re}[w(j \omega)]=0, \quad \operatorname{Im}[w(j \omega)]=0 .
$$

where $\operatorname{Re}[w(j \omega)]$ and $\operatorname{Im}[w(j \omega)]$ denote the real and the imaginary parts of (13), respectively. Finally, by solving the Equations (14) we obtain

$$
\begin{aligned}
& k_{d}=w^{1-\mu} \frac{w \sin \phi-\cos \phi}{\pi \sin \left(\frac{\pi \mu}{2}\right)} \\
& k_{p}=w \frac{\omega \sin \left(\frac{\pi \mu}{2}-\phi\right)+\cos \left(\frac{\pi \mu}{2}-\phi\right)}{k \sin \left(\frac{\pi \mu}{2}\right)}
\end{aligned}
$$

Equations (15) and (16) determine the complex zero boundary as a function of $\omega$. The real zero boundary and the complex zero boundary for $\omega \geq 0$ decompose plane $\left(k_{i}, k_{p}\right)$ into some regions. The stability region is chosen by testing an arbitrary point from each region and checking the stability of polynomial (12). In this paper only the stability region in the parameter plane of polynomial (12) is presented. When the stability regions are known, the tuning of the fractional controller can be carried out.

Taking into account the phase margin tester $\exp (-j \phi)$ in the main path of control, plant (1)and controller (3) for speed control we obtain the characteristic polynomial of the closed-loop system

$$
w(s)=e^{-j \phi} K\left(k_{p}+k_{i} s^{-\bar{\tau}}\right)+s \tau+1
$$

Using the classical $D$-partition method the stability region in the parameter plane $\left(k_{i}, k_{p}\right)$ may be determined and the parameters can be specified. The stability boundaries are curves on which each point corresponds to polynomial (17) having zeros on the imaginary axis. It may be the real zero boundary or the complex zero boundary. It is easy to see that polynomial (4) has zero $s=0$ if $k_{p}=0$ (the real zero boundary). The complex zero boundary corresponds to the pure imaginary zeros of (17). We obtain this boundary by solving the equation

$$
w(j \omega)=e^{-j \phi} K\left(k_{p}+k_{i}(j \omega)^{-\lambda}\right)+j \omega \tau+1=0,
$$

which we get by substituting $s=j \omega$ in polynomial (9) and equating to 0 . The complex Equation (10) can be rewritten as a set of real equations in the form 


$$
\operatorname{Re}[w(j \omega)]=0, \quad \operatorname{Im}[w(j \omega)]=0 .
$$

where $\operatorname{Re}[w(j \omega)]$ and $\operatorname{Im}[w(j \omega)]$ denote the real and the imaginar

Finally, by solving the Equations (19) we obtain

$$
\begin{gathered}
k_{i}=\frac{-(\sin \phi+w \pi \cos \phi) w^{\lambda}}{k \sin \left(\frac{\pi \lambda}{2}\right)} \\
k_{p}=\frac{\sin \left(\phi+\frac{\pi \lambda}{2}\right)(\sin \phi+1 w \cos \phi)+K w \sin ^{2}\left(\frac{\pi \lambda}{2}\right)}{k \sin \phi \sin \left(\frac{\pi \lambda}{2}\right)}
\end{gathered}
$$

Equations (12) and (13) determine the complex zero boundary as a function of $\omega$. The real zero boundary and the complex zero boundary for $\omega \geq 0$ decompose plane $\left(k_{i}, k_{p}\right)$ into some regions. The stability region is chosen by testing an arbitrary point from each region and checking the stability of polynomial (9). In this paper only the stability region in the parameter plane of polynomial (9) is presented. When the stability regions are known, the tuning of the fractional controller can be carried out.

A MATLAB GUI programs are developed the selection of control parameters for FOPID and PID controllers. Program outputs are output screen so that users enter the control parameters of PID controller as well as FOPID controllers. Control parameter values observed on the screen is obtained for $\mathrm{dc}$ motor speed control transfer function (1).Also this programs are used for dc motor position transfer function (2) by tuning control parameters of FOPID or PID controller.

\section{COMBINE POSITION AND SPEED PID REGULATOR}

Main guideline is to impose some additional control on the same system. Position PID regulator will stay unchanged. Imposed component is output signal from the speed controller shown in Figure 4. Speed controller will take effect on the whole system like additional differential component so coefficients in speed controller need to be the same order like differential component in position controller. Combined regulator shown in Figure 5 will be based on sum of responses of both position and speed regulators. Therefore combine regulator use two type PID controllers. PI controller is implemented for speed control and PD controller is used for position control. Also we can design combine position and speed fractional order PID regulator by implanting two fractional order PID controllers.

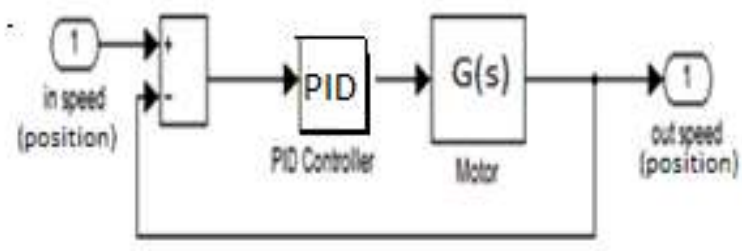

Fig 4 Block diagram of DC motor and position(speed) PID regulator

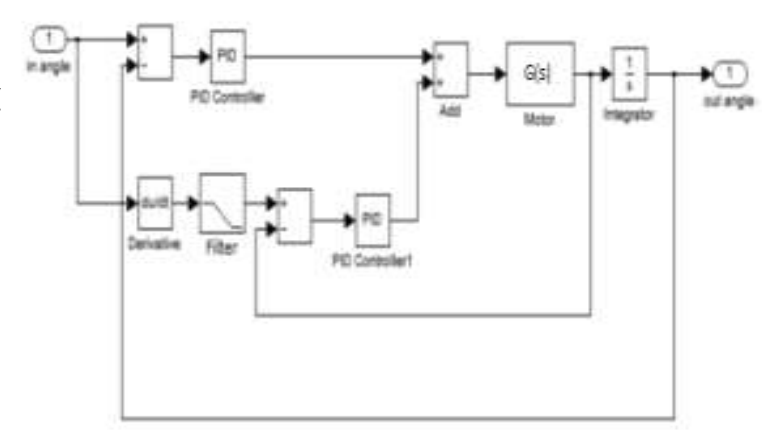

Fig. 5 MATLAB Block diagram of DC motor and combined position and speed regulator

\section{COMPUTER SIMULATIONS}

In this section, SIMULINK is used in the design of fractional order PID controller for both position and velocity controller of IPA and for modeling of IPA system. In order to compare the performance of classical PID and fractional order controllers two types SIMULINK diagrams are presented separately for both classical and fractional order controllers. In general PD controller is used for position control systems and PI controller is used for velocity control systems. In simulations both classical and fractional order PI and PD controllers are implemented

\section{A. FOPID Simulink Diagram}

FOPID control parameters are determined from the speed transfer function as on screen shown in Figure 6 . Also FOPID parameters can be similarly find for the position transfer function by using same method. Screen values for speed control is depicted in Figure. 6

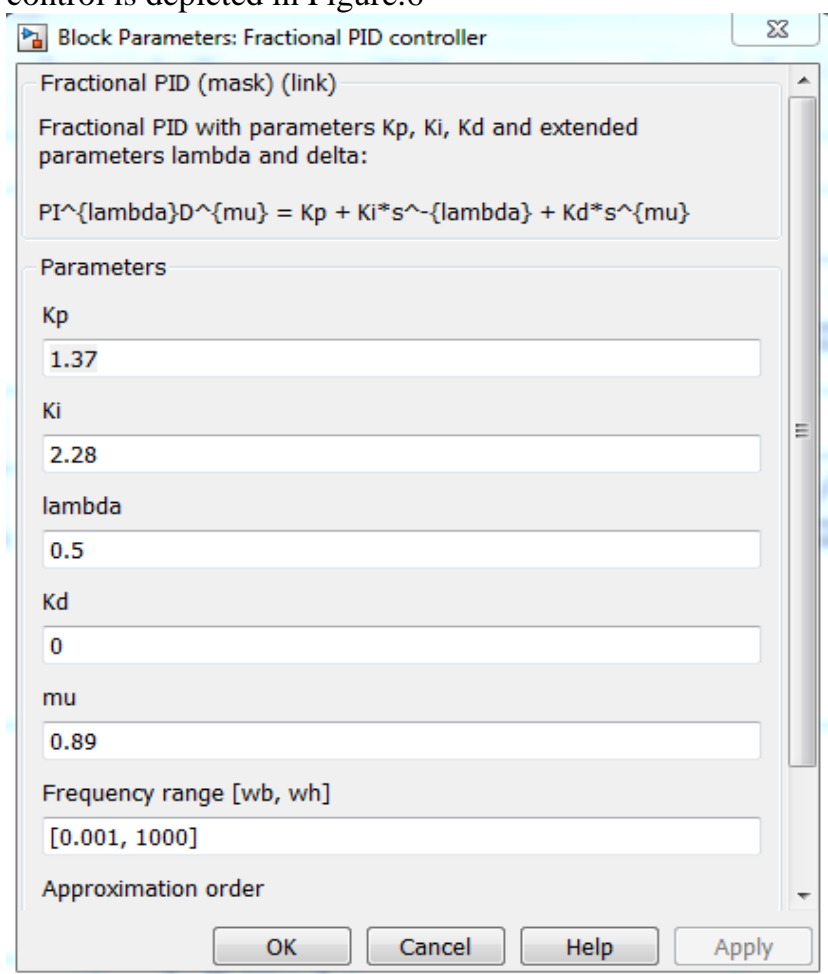

Fig 6 . FOPID control parameter values for speed control 
International Journal of Engineering and Technical Research (IJETR)

ISSN: 2321-0869 (O) 2454-4698 (P) Volume-8, Issue-6, June 2018

FOPID SIMULINK diagram for FOPID position and speed regulators is shown in Figure 7. In this diagram there are one input (reference input is position) and two outputs, position and velocity respectively. Velocity and position waveforms as a simulation results are depicted in Figure 8a, 8b.respectively.

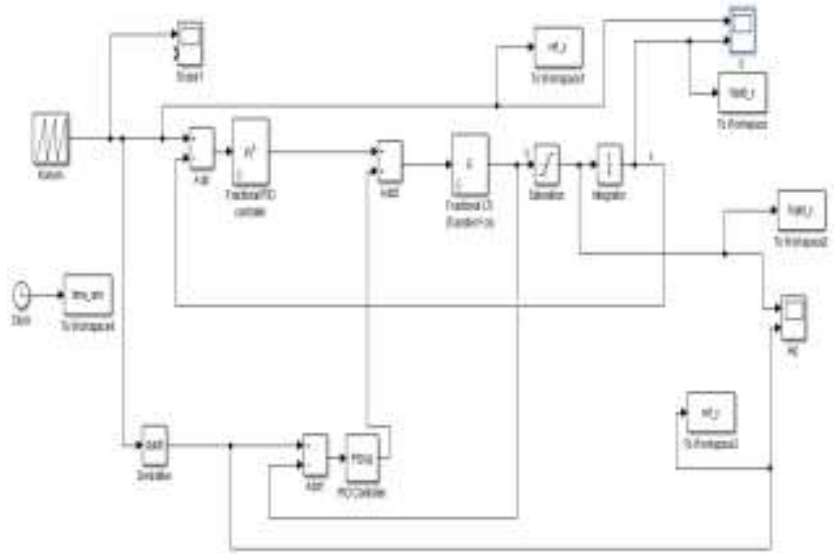

Fig 7. Fractional order PID SIMULINK diagram

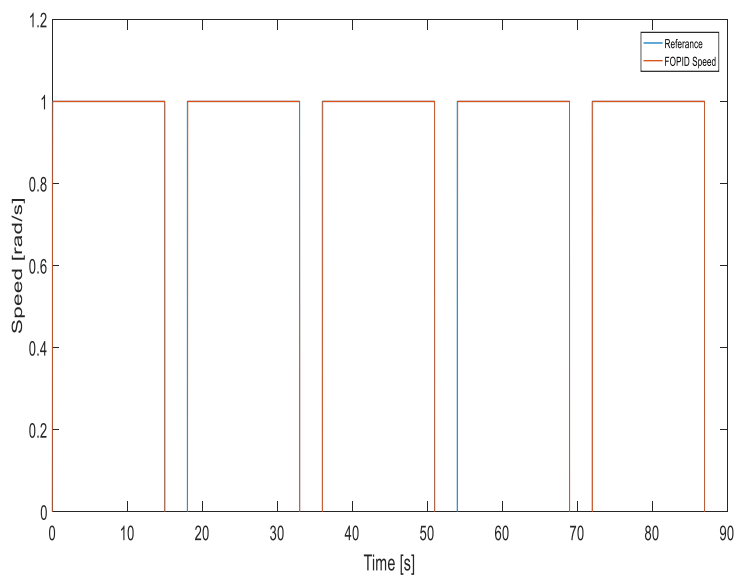

Fig 8a. FOPID velocity waveform of dc motor

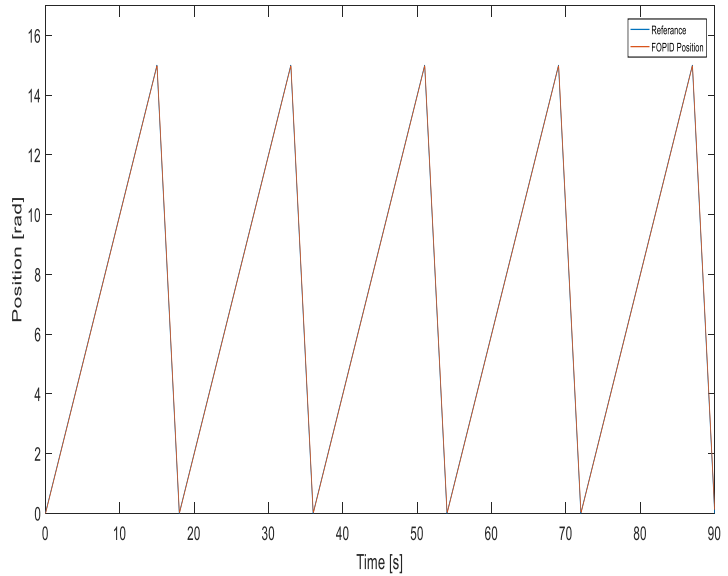

Fig 8b. FOPID Position Waveform Of Dc Motor

\section{B. PID Simulink Diagram}

MATLAB -GUI screen shown in Figure 9, which is developed in section 4 is used to choose control parameters for speed transfer function. PID control parameter values on the screen is choosen for $G(s)=\frac{0.25}{1.45 s+1}$ speed transfer function

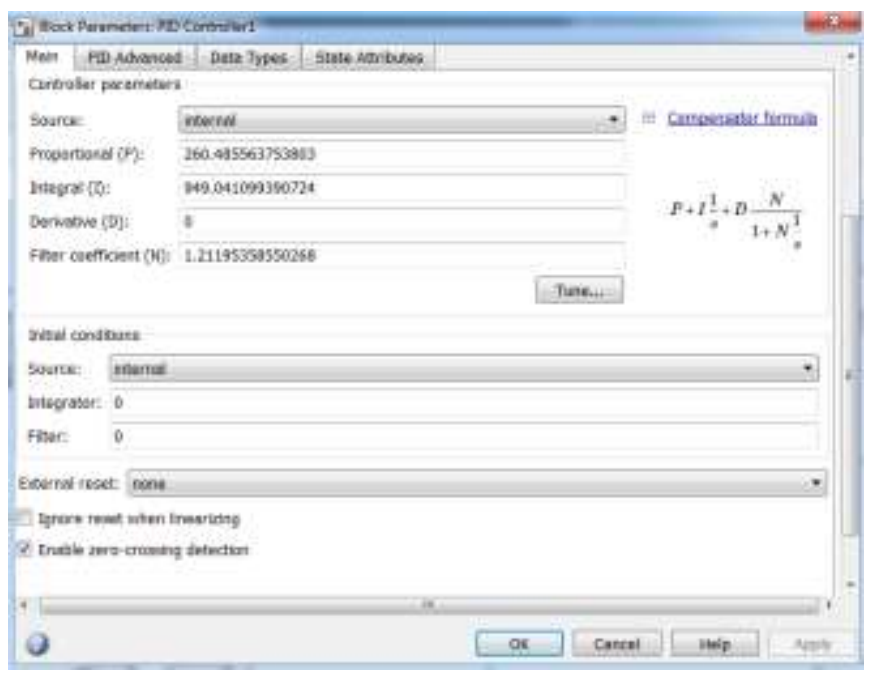

Fig 9. Classical PID control parameter values seen from output screen for speed control

PID SIMULINK diagram for PID controllers is shown in Figure 10. In this diagram there are one input (reference is position) and two outputs, position and velocity respectively. Velocity and position waveforms as a simulation results are depicted in Figure 11a, 11b respectively.

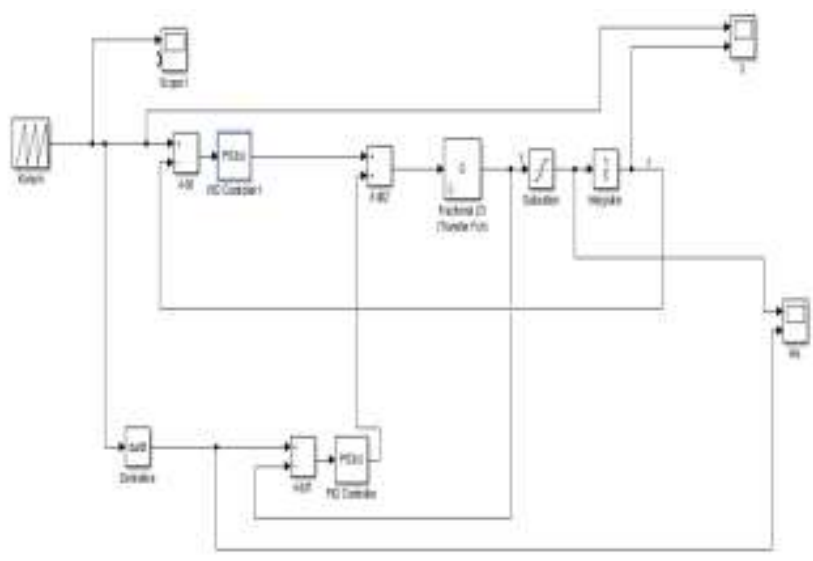

Fig 10. Classical PID SIMULINK diagram.

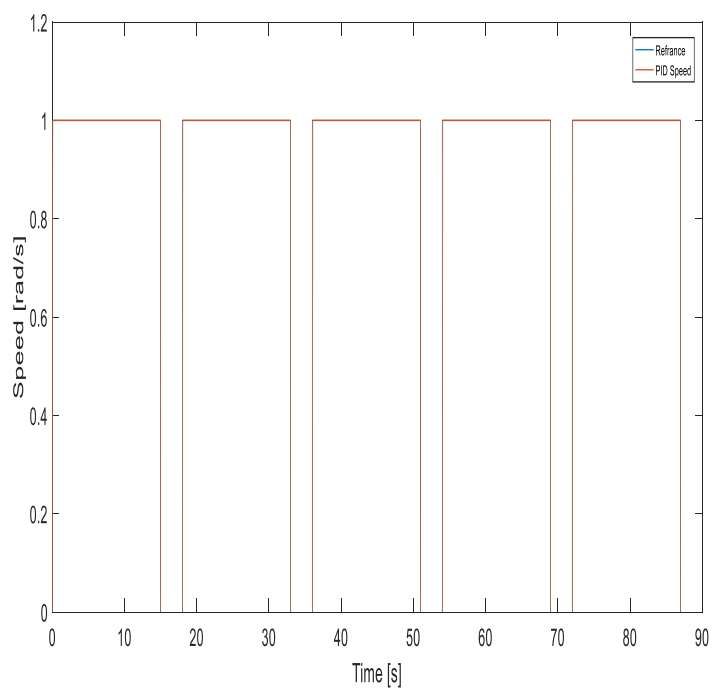

Fig 11a. Classical PID velocity waveform of dc motor. 


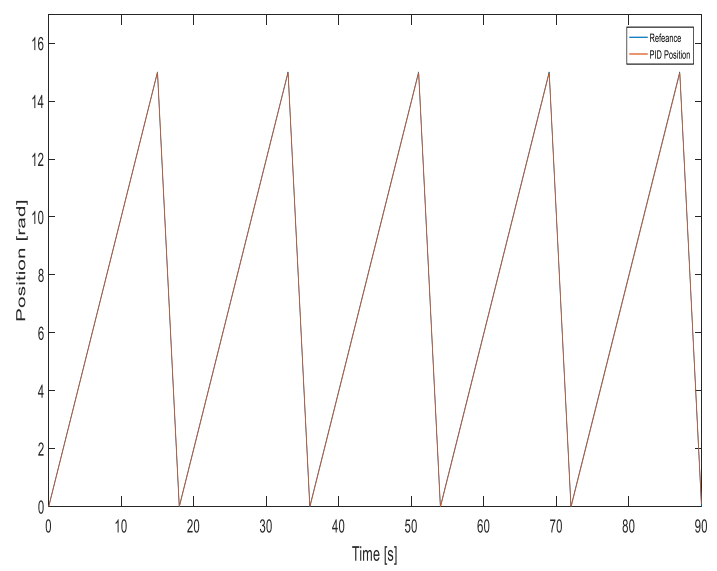

Fig 11b. Classical PID position waveform of dc motor

The Simulation results revealed good performances and show a stable and convergent behavior of the system when dealing with fractional order control law. The performances of both fractional order PI and PD controllers are analyzed and compared with integer order PI and PD controllers. The simulation results show that the fractional order controllers outperform the classical integer order controllers.

\section{VII: CONCLUSION}

In this paper, a design of a fractional order PI and PD controllers has been made to control the speed and position of a DC motor. The fractional order controllers were designed based on frequency domain specifications. The Simulation results revealed good performances and show a stable and convergent behavior of the system when dealing with fractional order control law. The performances of both fractional order PI and PD controllers are analyzed and compared with integer order PI and PD controllers. The simulation results show that the fractional order controllers outperform the classical integer order controllers.

Main guideline is to impose the some additional control on the same system. Position PID regulator will stay unchanged. Imposed component is output signal from the speed controller. Speed controller will take effect on the whole system like additional differential component so coefficients in speed controller need to be the same order like differential component in position controller. Combined regulator will be based on sum of responses of both position and speed regulators.

Having in mind obtained results, one can conclude that:

- Small signal bandwidth of both types of regulation will be the same but response of combined regulator will be smoother;

- On maximum requirements, combined regulation can produce more overshoot, but in biomedical application that type of signal will never be used in real situation;

- Combined regulation generates less noise for lower level of errors;
- Results show that by using combined controller we can reduce current consumption from battery. That will have as a benefit less heating in the system and possibility of longer flight for the same power supply in one system;

- Control alternation (change of type of control) could be done in software code - no hardware change needed.

\section{REFERENCES}

[1] Marinković, Z.; Marinković, D.; Petrović, G.; Milić, P. Modelling and Simulation of Dynamic Behaviour of Electric Motor Driven Mechanisms. // Tehnicki vjesnik-Techical Gazette. 19, 4(2012), pp. 717-725

[2] M. Steinbuch, R.J.E. Merry, M.L.G. Boerlage, M.J.C. Ronde and M.J.G. van de Molengraft, Ad- vanced Motion Control Design, In Levin, W.S. (Ed.), The Control Handbook, Control System Application, CRC Press, 2010

[3] M. Steinbuch, G. Schootstra and O.H. Bosgra, Robust control of a compact disc mechanism, In W.S. Levine (Ed.), Control System Applications (pp. 231-237). London: CRC Press, 2000.

[4] R.H. Bishop, The Mechatronics Handbook, CRC Press, 2002

[5] S.F. Yang, J.H. Chou, A mechatronic positioning system actuated using a micro DC - motor - driven propeller thruster, Mechatronics, 22, pp.1124-1134, 2012

[6] J. De Best, R. van de Molengraft, M. Steinbuch, A novel ball handling mechanism for the RoboCup middle size league, Mechatronics, 21(2), pp. 469-478, 2011

[7] Astrom K.J., Hagglund T., PID Controllers: Theory, Design, and Tuning. 2nd ed. Research Triangle Park, NC: Instrument Society of America (1995).

[8] K.J.Åström, and T. Hägglund, Advanced PID control, ISA-The Instrumentation, Systems, and Automation Society, 2006

[9] Petras I., Fractional-order feedback control of a DC motor. Journal of Electrical Engineering 60(3): 117-128 (2009).

[10] Petras I., Realization of fractional-order controller based on PLC and its utilization to temperature control. Transfer inovacii 14: $34-38$ (2009).

[11] Biswas A., Das, S, Abraham A., Dasgupta S., Design of fractional-order PI $\lambda \mathrm{D} \mu$ controllers with an improved differential evolution. Engineering Applications of Artificial Intelligence 22(2): 343-350 (2009).

[12] Caponetto R., Dongola G., Fortuna L., Gallo A., New results on the synthesis of FO-PID controllers, Communications in Nonlinear Science and Numerical Simulation 15(4): 997-1007 (2010).

[13] Castillo J., Feliu V., Rivas R., Sanchez L., Design of a class of fractional controllers from frequency specifications with guaranteed time domain behavior, Computers and Mathematics with Applications 59(5): 1656-1666 (2010).

[14] Luo Y., Chen Y.Q., Fractional order [proportional derivative] controller for a class of fractional order systems. Automatica 45(10): 2446-2450 (2009).

[15] Monje C.A., Vinagre B.M., Feliu V., Chen Y., Tuning and auto-tuning of fractional order controllers for industry applications. Control Engineering Practice 16: 798-812 (2008).

[16] Podlubny I., Fractional-order systems and PI $\lambda \mathrm{D} \mu$ controllers. IEEE Trans. on Automatic Control 44: 208-214 (1999).

[17] C.A. Monje, B. Vinagre, Y. Chen, V. Feliu, On fractional PI $\chi$ controllers: some tuning rules for robustness to plant uncertainties, Nonlinear Dynam., 38, pp. 369-381, 2004

[18]J. Villagra, B. Vinagre, I. Tejado, Data-driven fractional PID control: application to DC motors in flexible joints, Proceedings of the IFAC Conference on Advances in PID Control PID' 12, Brescia(Italy), 2012

[19] C.I. Muresan, S. Folea, G. Mois, E.H.Dulf, Development and implementation of an FPGA based

fractional order controller for a DC motor, Mechatronics,23(7), pp. 798-804, 2013

[20] C.A. Monje, Y. Chen, B.M. Vinagre, D. Xue,V. Feliu, Fractional-order Systems and Controls, Fundamentals and Applications, Springer, London, 2010

[21] R. Singhal, S. Padhee, G. ,G. Kaur, Design of Fractional order PID controller for speed control of dc motor, International Journal of Scientific and Research Publications, Volume 2, Issue 6, June 2012, ISSN 2250-3153 
[22] J. Poovarasan, B. Ramireddy, R. Kayalvizhi, Design and Implementation of fractional order controllers for dc motor position servo system, American Jr. Mathematics and Sciences, Vol.1, No.1, pp.169-173, (.2012)

\section{Author Profiles}

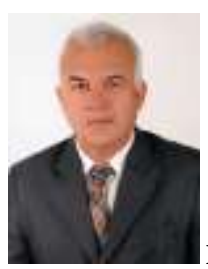

Mahmut ÜN He received MS degree and $\mathrm{Ph}$. D from Electrical Engineering Faculty, İstanbul Technical University in 1973 and 1983 respectively. His research area is Control System Engineering and Biomedical Engineering. Now he is working with İstanbul Yeni Yüzyıl Üniversity. He published More than 20 journal papers, more than 10 international conference papers in English and more than 5 national journal papers, more than 12 national conference papers and 5 books. $\mathrm{He}$ is a membership of EMO and IEEE.

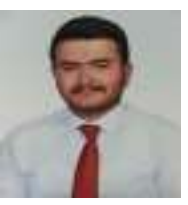

Çağlar ÇIFTÇíOĞLU In 2015 and 2018, respectively, he received a Bachelor of Biomedical Engineering degree and a Master of Biomedical Engineering degree. He is working on biomedical control systems. Now he is working as a lecturer at İstanbul Gelişim University 